\title{
Febre catarral maligna em bovinos no Rio Grande do Sul: epidemiologia, sinais clínicos e patologia ${ }^{1}$
}

\author{
Raquel R. Rech ${ }^{2}$, Ana Lucia Schild ${ }^{3}$, David Driemeier ${ }^{4}$, Shana L. Garmatz ${ }^{2}$, Fabiano \\ N. Oliveira ${ }^{2}$, Franklin Riet-Correa ${ }^{5}$ e Claudio S.L. Barros ${ }^{6 "}$
}

\begin{abstract}
Rech R.R., Schild A.L., Driemeier D., Garmatz S.L., Oliveira F.N., Riet-Correa F \& Barros C.S.L. 2005. [Malignant catarrhal fever in cattle in Rio Grande do Sul, Brazil: Epidemiology, clinical signs and pathology.] Febre catarral maligna em bovinos no Rio Grande do Sul: epidemiologia, sinais clínicos e patologia. Pesquisa Veterinária Brasileira 25(2):97-105. Depto Patologia, Universidade Federal de Santa Maria, 97105-900 Santa Maria, RS, Brazil. E-mail: claudioslbarros@uol.com.br

The epidemiology, clinical signs, necropsy and histopathological findings in cases of malignant catarrhal fever (MCF) occurring in cattle from 15 farms in Rio Grande do Sul, Brazil, from 1973 to 2003, are described. In 9 instances (60\%) the disease occurred as sporadic cases affecting 1-3 cattle whereas in six farms (40\%) MCF occurred as epizootics involving several cattle in each affected herd. Morbidity rates ranged from $2.4 \%$ to $20 \%$ and lethality rates were $83.3 \%$ and $100 \%$. Cattle of all ages and both sexes were affected. Where the information was available ( 9 farms) sheep were in contact with affected cattle and cases of MCF occurred more frequently in spring and summer. Clinical courses were acute or subacute and clinical signs included fever, nasal and ocular discharges, conjunctivitis, drooling, hematuria, necrosis and blunting of buccal papillae, enlargement of lymph nodes, diarrhea and neurological disturbances. Necropsy findings included opaque corneas, reddening, erosions and ulcerations in several mucous membranes of the alimentary, respiratory and urogenital tracts, and the conjunctiva; enlargement and haemorrhage of lymph nodes and multiple white foci in the renal cortices and in the hepatic portal triads. Crustous dermatitis was observed in some cases. Main histopathological findings included vasculitis, necrosis of the surface epithelia and accumulation of inflammatory cells in several organs. Vasculitis were associated with fibrinoid necrosis of the medial layer of arteries and inflammatory cells included lymphoblasts, lymphocytes, plasma cells and macrophages.
\end{abstract}

INDEX TERMS: Infectious diseases, epidemiology, viral diseases, diseases of cattle, pathology.

${ }^{1}$ Recebido em 22 de julho de 2004.

Aceito para publicação em 29 de julho de 2004.

Realizado com apoio financeiro do Programa de Apoio a Núcleos de Excelência (PRONEX), Proc. CNPq 661069/1997. Parte da Dissertação de Doutorado do primeiro autor.

${ }^{2}$ Programa de Pós-Graduação em Medicina Veterinária, área de concentração em Patologia Veterinária, Centro de Ciências Rurais, Universidade Federal de Santa Maria (UFSM).

${ }^{3}$ Laboratório Regional de Diagnóstico. Faculdade de Veterinária. Universidade Federal de Pelotas, 96010-900, Pelotas, RS.

${ }^{4}$ Departamento de Patologia Clínica Veterinária, Setor de Patologia Veterinária, Universidade Federal do Rio Grande do Sul, Caixa Postal 15094, Porto Alegre, RS 91540-000.

${ }^{5}$ Centro de Saúde e Tecnologia Rural, Universidade Federal de Campina Grande, Campus de Patos, 58700-00 Patos, PB.

${ }^{6}$ Departamento de Patologia, UFSM, 97105-900 Santa Maria, RS. "Autor para correspondência. E-mail: claudioslbarros@uol.com.br
RESUMO.- São descritos a epidemiologia, os sinais clínicos e os achados de necropsia e histopatológicos observados em casos de febre catarral maligna (FCM), que ocorreram de 1973 a 2003 em bovinos de 15 fazendas no Rio Grande do Sul. Em nove ocasiões $(60 \%)$, a doença ocorreu de forma esporádica, afetando 1-3 bovinos por rebanho, enquanto, em seis fazendas (40\%), a FCM ocorreu de forma epizoótica, afetando vários bovinos em cada rebanho. As taxas de morbidade variaram de $2,4 \%$ a $20 \%$, e as taxas de letalidade foram de $83,3 \%$ a $100 \%$. Bovinos de todas as idades e ambos os sexos foram afetados. Nos casos em que foi possível obter essa informação ( 9 fazendas), sempre havia ovinos em contato com os bovinos afetados, e o maior número de casos de FCM ocorreu na primavera e verão. A doença clínica era aguda ou subaguda, e os sinais clínicos incluíam febre, corrimento nasal e ocular, conjuntivite, salivação excessiva, 
hematúria, necrose das papilas bucais que se tornavam rombas, linfadenopatia, diarréia e distúrbios neurológicos. Os achados de necropsia incluíam opacidade da córnea, erosões e ulcerações em várias membranas mucosas do trato alimentar, respiratório, urogenital e conjuntiva; aumento de volume e hemorragia em linfonodos e múltiplos focos brancos nos córtices renais e nas tríades portais hepáticas. Dermatite crostosa foi observada em alguns casos. Os principais achados histopatológicos inclúam vasculite, necrose dos epitélios de revestimento e acúmulos de células inflamatórias em vários órgãos. A vasculite era associada com necrose fibrinóide da túnica média das artérias e acompanhada de infiltrado inflamatório constituído por linfoblastos, linfócitos, plasmócitos e macrófagos.

TERMOS DE INDEXAÇÃO: Doenças infecciosas, epidemiologia, doenças a vírus, doenças de bovinos, patologia.

\section{INTRODUÇÃO}

A febre catarral maligna (FCM) é uma doença infecciosa viral, pansistêmica de bovinos e outros ruminantes domésticos e silvestres (Smith 2002) e, ocasionalmente, suínos (Løken et al. 1998). Os sinais clínicos aparecem após um período de incubação de 3 a 10 semanas e incluem erosões e úlceras orais e nasais, febre alta, opacidade da córnea, corrimento nasal mucopurulento, salivação, diarréia, ceratoconjuntivite, linfadenopatia, diarréia, distúrbios nervosos e exantema cutâneo (Smith 2002). As lesões macroscópicas envolvem principalmente os tratos digestivo, respiratório superior e urinário, linfonodos, fígado, olhos e

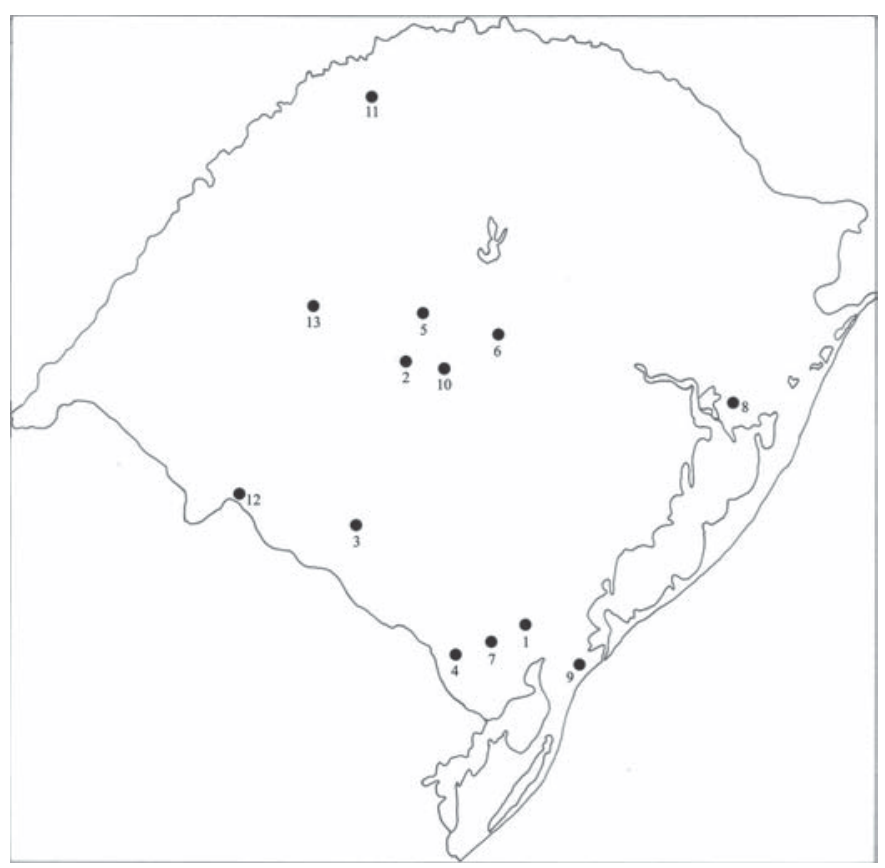

Fig. 1. Localização dos 13 municípios do Rio Grande do Sul onde foram observados os casos de febre catarral maligna descritos neste trabalho. (1) Capão do Leão, (2) Dilermando de Aguiar, (3) Dom Pedrito, (4) Herval, (5) Júlio de Castilhos, (6) Nova Palma, (7) Pedro Osório, (8) Porto Alegre, (9) Rio Grande, (10) Santa Maria, (11) Santa Rosa, (12) Santana do Livramento e (13) Santiago. encéfalo e incluem lesões erosivo-ulcerativas em várias mucosas (Barker et al. 1993). Histologicamente, as lesões consistem de vasculite com necrose fibrinóide, infiltrados mononucleares em vários órgãos, hiperplasia linfóide e necrose dos epitélios de revestimento e são consideradas patognomônicas ou muito características para a doença (Barker et al. 1993, Garmatz et al 2004). Os "vírus do grupo da FCM" pertencem ao gênero Rhadinovirus da família Gammaherpesvirinae. A forma africana, ou FCM gnu-associada (FCM-GA), é induzida pela cepa Alcelaphine Herpesvírus 1 (AlHV-1) e transmitida por gnus. A forma denominada FCM ovino-associada (FCM-OA), transmitida por ovinos, é causada por herpesvírus ovino-2 - OvHV-2 (Garmatz et al. 2004). Embora a FCM tenha sido documentada em bovinos de várias regiões do Brasil, como Nordeste (Torres 1924, Döbereiner \& Tokarnia 1959, Oliveira et al. 1978, Figueiredo et al. 1990, Silva 2001, Riet-Correa et al. 2003), Sudeste (Sampaio et al. 1972, Marques et al. 1986) e Sul (Barros et al. 1983, Riet-Correa et al. 1988, Baptista \& Guidi 1998, Garmatz et al. 2004), os relatos são esparsos e não há uma documetação abrangente que determine as taxas de morbidade, mortalidade e letalidade e outros aspectos epidemiológicos e patológicos da FCM

Esse trabalho relata a epidemiologia, os sinais clínicos, achados de necropsia e histopatológicos de 15 surtos de FCM ocorridos no Rio Grande do Sul, afetando 223 bovinos de uma população sob risco de aproximadamente 2.000 bovinos. As lesões macroscópicas e histopatológicas foram compiladas de 24 necropsias realizadas nos bovinos que morreram nesses surtos.

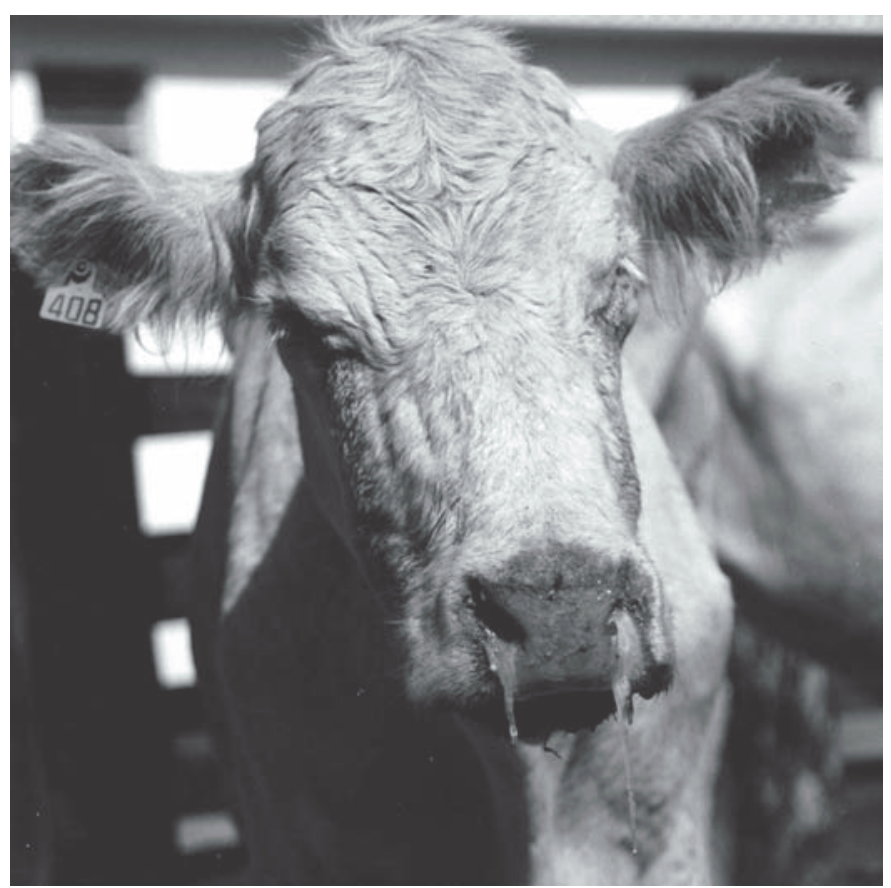

Fig. 2. Febre catarral maligna em bovinos no Rio Grande do Sul. Sinais clínicos. Corrimento nasal muco-purulento em ambas as narinas. 


\section{MATERIAL E MÉTODOS}

Os arquivos dos laboratórios de patologia veterinária da Universidade Federal de Santa Maria, da Universidade Federal do Rio Grande do Sul e do Laboratório Regional de Diagnóstico da Universidade Federal de Pelotas foram revisados à procura de casos de FCM em bovinos. Foram anotados dados referentes à epidemiologia, aos sinais clínicos, às alterações de necropsia e à histopatologia. Os dados epidemiológicos e clínicos haviam sido colhidos através de visitas às propriedades onde ocorriam os casos. Nessas ocasiões, foram feitas necropsias e foi colhido material para histopatologia. Os critérios mínimos para confirmação dos casos consistiram de dados epidemiológicos, exame clínico, necropsia e histopatologia. Em duas propriedades, o diagnóstico foi confirmado adicionalmente por deteç̧ão do DNA viral em tecidos de animais afetados, pela técnica de reação em cadeia de polimerase (PCR) e, em um dos surtos, a doença foi transmitida experimentalmente a bovinos suscetíveis pela injeção intravenosa de sangue total de bovino afetado na fase aguda da FCM. Detalhes do diagnóstico por PCR e da transmissão da doença a bovinos nesses dois surtos já foram publicados (Garmatz et al. 2004).

\section{RESULTADOS}

\section{Epidemiologia}

De 1973 a 2003 , foram encontrados 15 relatos de epizootias ou ocorrências esporádicas de FCM em bovinos de 15 propriedades rurais de 13 municípios das regiões sul, centro e leste do Rio Grande do Sul (Fig. 1). As propriedades onde ocorreram os casos de FCM em bovinos foram numeradas de 1-15 em forma cronológica decrescente de ocorrência (Quadro 1). Em 9 (60,0\%) dessas fazendas (Propriedades 1, 2, 4, 5, 7, 9, 10, 12 e 14), a doença ocorreu de forma esporádica afetando um (8 propriedades) ou três (uma propriedade) bovinos por rebanho. Em seis $(40,0 \%)$ fazendas (Propriedades $3,6,8,10,13$ e 15$)$ a doença ocorreu sob forma de epizootias, afetando vários bovinos num rebanho. O surto epizoótico de maiores proporções ocorreu na Propriedade 10 em Santana do Livramento, onde morreram 100 bovinos de dois anos de idade ao longo de um ano.
Em 10 fazendas (Propriedades 1-4, 6, 8, 11, 13-15) os dados disponíveis permitiram o cálculo da morbidade que foi, respectivamente, 5,0\%, 5,0\%, 2,4\%, 6,7\%, 10,6\%, 2,5\%, 14,3\%, 6,2\%, 25\% e $20 \%$. As taxa de letalidade observadas foram, quase invariavelmente, de $100 \%$, mas, na Propriedade 6, pelo menos três bovinos afetados sobreviveram (letalidade de $83,3 \%$ ). Dados relativos à idade dos bovinos afetados estavam anotados em 8 dos 15 dos protocolos de registro; variaram de 18 meses a 10 anos. Com exceção de uma vaca da Propriedade 6 , que tinha 10 anos de idade, todos os outros bovinos afetados tinham 4 anos de idade ou menos. Ambos os sexos foram afetados igualmente.

Em nove ocasiões (Propriedades 2-4, 7, 11, 12, 14-16), havia ovelhas em contato com os bovinos; em outras seis (Propriedades $5,7,8,9,10,12$ ), essa informação não constava nos protocolos. A maioria dos casos de FCM ocorreu na primavera e no verão, no entanto, foram registrados casos no inverno em três oportunidades (Propriedades 8, 11 e 12), e numa oportunidade (Propriedade 10), mortes por FCM ocorreram durante um período de um ano após o primeiro diagnóstico em outubro de 1999.

\section{Sinais clínicos}

Os sinais clínicos apresentados pelos bovinos afetados, nas 15 propriedades de surtos ou ocorrências esporádicas de FCM no Rio Grande do Sul, estão no Quadro 2. A doença apresentou um curso agudo ou subagudo e, na maioria das vezes, fatal. Os sinais clínicos iniciavam por febre, corrimento nasal e ocular seroso e edema da pálpebra e conjuntiva. O corrimento nasal evoluía rapidamente para corrimento muco-purulento espesso (Fig. 2) e ocorria opacidade da córnea. Sialorréia, necrose das papilas bucais, lesões erosivo-ulcerativas na cavidade oral, linfadenopatia, conjuntivite e diarréia foram outros sinais observados. Desprendimento da capa córnea dos cascos foi observado em um caso, e hematúria, em outro. Distúrbios nervosos foram observados em bovinos de 9 das 15 propriedades (60\%). Os sinais clínicos de distúrbios nervosos freqüentemente relata-

Quadro 1. Dados epidemiológicos dos casos de febre catarral maligna diagnosticados em bovinos no Rio Grande do Sul

\begin{tabular}{|c|c|c|c|c|c|c|}
\hline \multirow{2}{*}{$\begin{array}{l}\text { Município de ocorrência } \\
\text { (№ do relato) }\end{array}$} & \multirow{2}{*}{$\begin{array}{c}\text { Contato com } \\
\text { ovinos }\end{array}$} & \multirow[t]{2}{*}{ Mês } & \multirow[t]{2}{*}{ Ano } & \multicolumn{3}{|c|}{ Número de bovinos } \\
\hline & & & & Sob risco & Doentes & Mortos \\
\hline Capão do Leão (1) & Sim & Maio & 2003 & 20 & 1 & 1 \\
\hline Rio Grande (2) & Sim & Janeiro & 2003 & 70 & 1 & 1 \\
\hline Santiago $^{a}(3)$ & Sim & Janeiro/fevereiro & 2003 & 500 & 12 & 12 \\
\hline Santa Rosa (4) & Sim & Março & 2003 & 15 & 1 & 1 \\
\hline Santa Maria (5) & n.i. ${ }^{b}$ & Outubro & 2003 & n.i. & 1 & 1 \\
\hline Santiago $^{\mathrm{a}}(6)$ & Sim & Novembro/fevereiro & $2001 / 2002$ & 170 & 18 & 15 \\
\hline Dilermando de Aguiar (7) & n.i. & Novembro & 2000 & n.i. & 1 & 1 \\
\hline Dom Pedrito (8) & n.i. & Junho & 1999 & 480 & 12 & 12 \\
\hline Nova Palma (9) & n.i. & Setembro & 1999 & n.i. & 1 & 1 \\
\hline Santana do Livramento (10) & n.i. & Outubro $^{c}$ & 1999 & n.i. & 100 & 100 \\
\hline Porto Alegre (11) & Sim & Junho & 1997 & 7 & 1 & 1 \\
\hline Pedro Osório (12) & n.i. & Março/junho/novembro & 1994 & n.i. & 3 & 3 \\
\hline Santiago (13) & Sim & Novembro & 1994 & 470 & 29 & 29 \\
\hline Herval (14)Sim & Dezembro & 1987 & 4 & 1 & 1 & \\
\hline Júlio de Castilhos ${ }^{\mathrm{d}}$ (15) & Sim & Fevereiro/março & 1973 & 200 & 40 & 40 \\
\hline
\end{tabular}

aAnteriormente publicado (Garmatz et al. 2004); bnão informado; ${ }^{\mathrm{c}}$ data do diagnóstico; danteriormente publicado (Barros et al. 1983). 
Quadro 2. Sinais clínicos nos casos de febre catarral maligna diagnosticados em bovinos no Rio Grande do Sul

\begin{tabular}{|c|c|}
\hline $\begin{array}{c}\text { Localização } \\
\text { (No. do relato) }\end{array}$ & Sinais clínicos \\
\hline Capão do Leão (1) & Febre, opacidade da córnea, cegueira, ulceração no focinho e mucosa oral, incoordenação motora, decúbito \\
\hline Rio Grande (2) & Febre, opacidade da córnea, corrimento nasal e ocular seroso, erosões labiais, distúrbios nervosos \\
\hline Santiago (3) & $\begin{array}{l}\text { Febre, opacidade da córnea, edema das pálpebras, hiperemia da mucosa nasal e conjuntiva, corrimento } \\
\text { nasal e ocular seroso ou mucopurulento, diarréia, linfadenopatia, distúrbios nervosos }\end{array}$ \\
\hline Santa Rosa (4) & Opacidade da córnea, corrimento ocular seroso, diarréia \\
\hline Santa Maria (5) & Separação do lote, opacidade da córnea, distúrbios nervosos \\
\hline Santiago (6) & $\begin{array}{l}\text { Febre, opacidade da córnea, edema das pálpebras, hiperemia da mucosa nasal e conjuntiva, corrimento } \\
\text { nasal e ocular seroso ou mucopurulento, erosões labiais, sialorréia, erosões e corrimento vulvar, hematúria, } \\
\text { diarréia, linfadenopatia, distúrbios nervosos }\end{array}$ \\
\hline Dilermando de Aguiar (7) & $\begin{array}{l}\text { Opacidade da córnea, corrimento nasal e ocular mucopurulento, necrose do ápice das papilas bucais, } \\
\text { desprendimento da capa córnea dos cascos e dígitos acessórios }\end{array}$ \\
\hline Dom Pedrito (8) & Distúrbios nervosos \\
\hline Nova Palma (9) & Febre, anorexia, diarréia, distúrbios nervosos \\
\hline Livramento (10) & Não informado \\
\hline Porto Alegre (11) & Opacidade da córnea, corrimento nasal e ocular mucopurulento, erosões na mucosa oral, hematúria \\
\hline Pedro Osório (12) & Corrimento nasal, erosões no focinho, sialorréia \\
\hline Santiago (13) & Opacidade da córnea, diarréia, distúrbios nervosos \\
\hline Herval (14) & $\begin{array}{l}\text { Febre, opacidade da córnea, hiperemia da conjuntiva, corrimento nasal purulento, desprendimento do } \\
\text { epitélio nasal e do focinho, erosões na mucosa oral, sialorréia, desprendimento capa córnea dos cascos e } \\
\text { dígitos acessórios, linfadenopatia, distúrbios nervosos }\end{array}$ \\
\hline Júlio de Castilhos (15 & $\begin{array}{l}\text { Opacidade de córnea, edema das pálpebras, hiperemia da mucosa nasal e conjuntiva, corrimento nasal } \\
\text { mucopurulento, sialorréia, hiperemia e exsudato fibrinonecrótico na mucosa do prepúcio, distúrbios } \\
\text { nervosos }\end{array}$ \\
\hline
\end{tabular}

dos inclúam apatia, incoordenação, hipermetria, tremores musculares, agressividade, cegueira, quedas, opistótono, movimentos de pedalagem e convulsões.

\section{Achados de necropsia}

Os principais achados de necropsia incluíam lesões nos tratos digestivo, respiratório superior e urinário (Quadro 3). Adici-

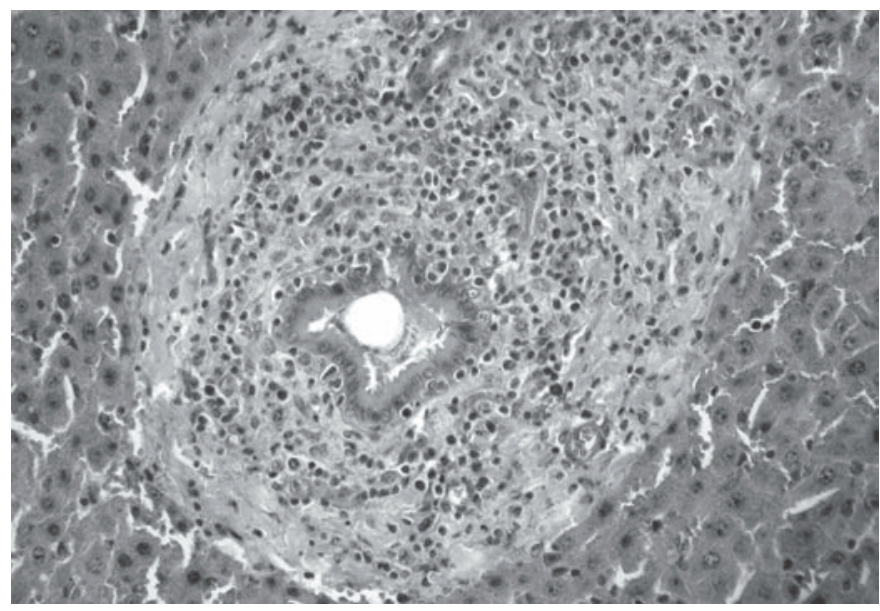

Fig. 3. Febre catarral maligna em bovinos no Rio Grande do Sul. Aspecto histológico de um espaço porta com infiltrado inflamatório mononuclear. $\mathrm{HE}$, obj. 40. onalmente, as lesões observadas clinicamente (por ex., opacidade da córnea) foram também confirmadas na necropsia. Lesões características desses casos de FCM foram hiperemia, erosões e ulcerações em várias superfícies mucosas do trato alimentar, respiratório, urinário e genital, aumento de volume dos linfonodos que, por vezes, tinham aspecto hemorrágico, e múltiplos focos brancos de infiltrado inflamatório no rim e nos espa-

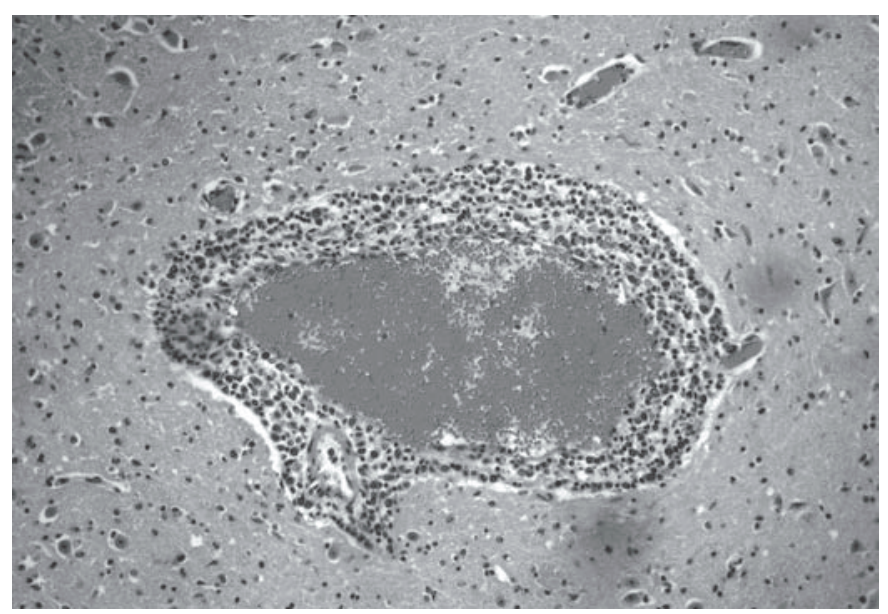

Fig. 4. Febre catarral maligna em bovinos no Rio Grande do Sul. Aspectos histopatológicos. Encéfalo. Manguito perivascular mononuclear na substância subcortical do córtex telencefálico. HE, obj. 25. 
Quadro 3. Achados de 24 necropsias de casos de febre catarral maligna diagnosticados em bovinos no Rio Grande do Sul

\begin{tabular}{|c|c|}
\hline $\begin{array}{l}\text { Localização } \\
\text { (No. do relato) }\end{array}$ & Achados de necropsia \\
\hline Capão do Leão (1) & $\begin{array}{l}\text { Opacidade da córnea, ulcerações no focinho, mucosa oral, esôfago e abomaso, aumento de tamanho dos linfonodos } \\
\text { mesentéricos e petéquias na mucosa da bexiga. }\end{array}$ \\
\hline Rio Grande (2) & Erosões e ulcerações na gengiva, lábios, palato e língua \\
\hline Santiago (3) & $\begin{array}{l}\text { Erosões/úlceras nos cornetos nasais, necrose das papilas bucais, aumento de volume dos linfonodos, focos pálidos } \\
\text { na cortical renal }\end{array}$ \\
\hline Santa Rosa (4) & Não informado \\
\hline Santa Maria (5) & Focos pálidos na cortical renal, úlceras na mucosa do abomaso \\
\hline Santiago (6) & $\begin{array}{l}\text { Erosões/úlceras nos cornetos nasais, erosões/úlceras na cavidade oral, necrose das papilas bucais, aumento de } \\
\text { volume doa linfonodos, erosões/úlceras no abomaso, hemorragia/úlceras no intestino, focos pálidos no rim, } \\
\text { hemorragia/edema na bexiga, hiperemia das leptomeninges }\end{array}$ \\
\hline Dilermando de Aguiar (7) & $\begin{array}{l}\text { Erosões e miíase na cavidade nasal, aumento de volume dos linfonodos, placas de Peyer aumentadas de volume e } \\
\text { avermelhadas, úlceras na traquéia, esôfago, abomaso e intestino grosso, fígado com padrão reticular, múltiplos } \\
\text { focos pálidos na cortical renal, mucosa da bexiga avermelhada }\end{array}$ \\
\hline Dom Pedrito (8) & Não informado \\
\hline Nova Palma (9) & Edema e congestão pulmonar, exsudato mucopurulento na traquéia e brônquios, fígado aumentado de volume e pálido \\
\hline Livramento (10) & Não informado \\
\hline Porto Alegre (11) & Erosões na cavidade oral e no esôfago, aumento de volume dos linfonodos, hemorragia na mucosa da bexiga \\
\hline Pedro Osório (12) & Autólise \\
\hline Santiago (13) & $\begin{array}{l}\text { Hiperemia dos espaços interdigitais, úlceras na mucosa oral e língua, necrose das papilas bucais, hiperemia e } \\
\text { erosões dos cornetos nasais, aumento de volume dos linfonodos, mucosa intestinal hiperêmica com focos recobertos } \\
\text { por fibrina, múltiplos focos pálidos na cortical renal, edema na bexiga, edema da vulva e vagina, hiperemia das } \\
\text { leptomeninges }\end{array}$ \\
\hline Herval (14) & $\begin{array}{l}\text { Úlceras e congestão da mucosa oral, língua, glote, do esôfago, rúmen e intestino; hiperemia da mucosa dos } \\
\text { cornetos, úlceras na mucosa nasal, edema das leptomeninges }\end{array}$ \\
\hline Júlio de Castilhos (15) & $\begin{array}{l}\text { Hiperemia da conjuntiva, humor vítreo floculento e turvo, corrimento ocular seroso, úlceras recobertas por fibrina } \\
\text { na cavidade nasal, exsudato mucopurulento nas fossas nasais, crostas nas narinas, linfonodos aumentados de } \\
\text { volume e hemorrágicos, hiperemia e ulcerações na mucosa do abomaso, fígado aumentado de volume com } \\
\text { acentuação do padrão lobular; múltiplos focos pálidos na cortical renal, petéquias e edema na mucosa da bexiga }\end{array}$ \\
\hline
\end{tabular}

ços-porta do fígado; essa última alteração dava um aspecto reticular à superfície (natural e de corte) hepática. As lesões oculares foram bastante freqüentes e, portanto, características da doença.

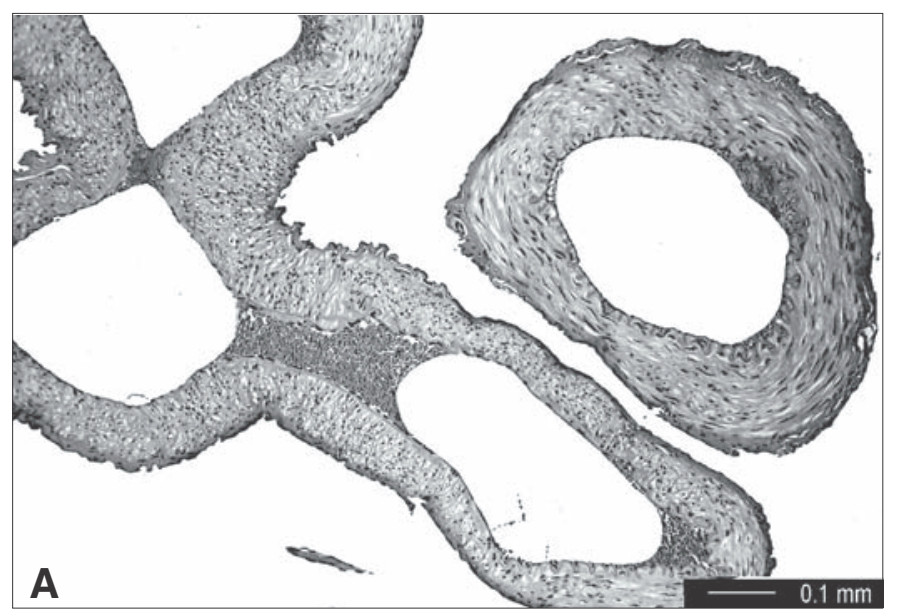

\section{Achados histológicos}

Os principais alterações histológicas, nas 15 propriedades de surtos ou ocorrências esporádicas de casos de FCM no Rio Grande do Sul, constam no Quadro 4. Em geral, esses

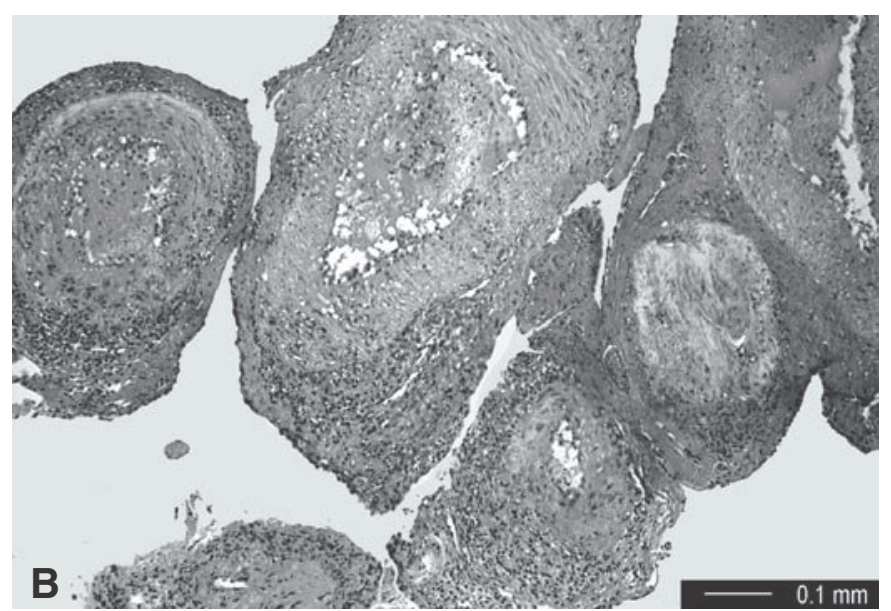

Fig. 5. Febre catarral maligna (FCM) em bovinos no Rio Grande do Sul. Aspecto histológico das lesões vasculares na rete mirabile carotídea. (A) Bovino normal. (B) Bovino com FCM. Infiltrado inflamatório mononuclear acentuado na parede das artérias, predominantemente na adventícia. HE, obj. 25. 
Quadro 4. Achados histológicos nos casos de febre catarral maligna diagnosticados em bovinos no Rio Grande do Sul

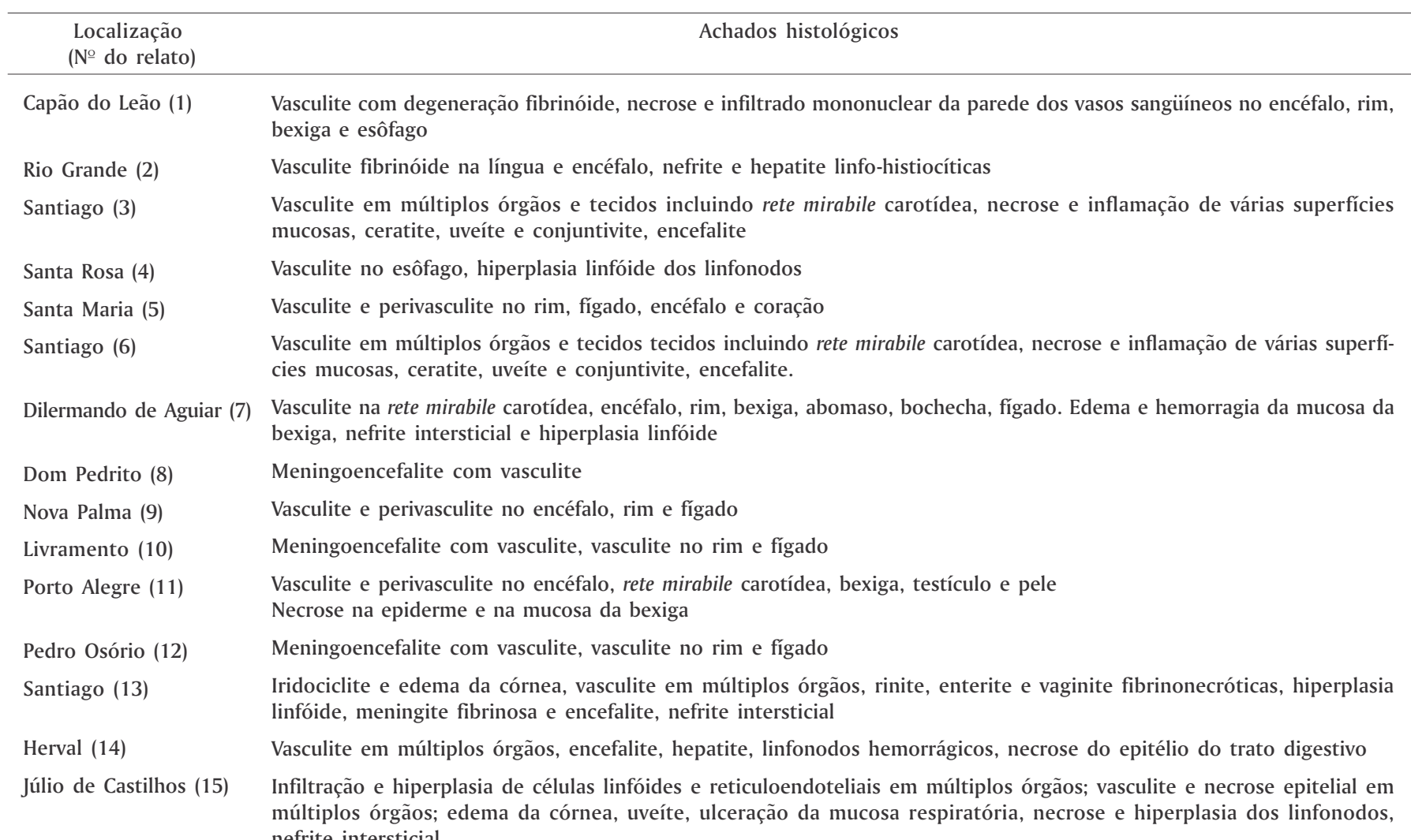
nefrite intersticial
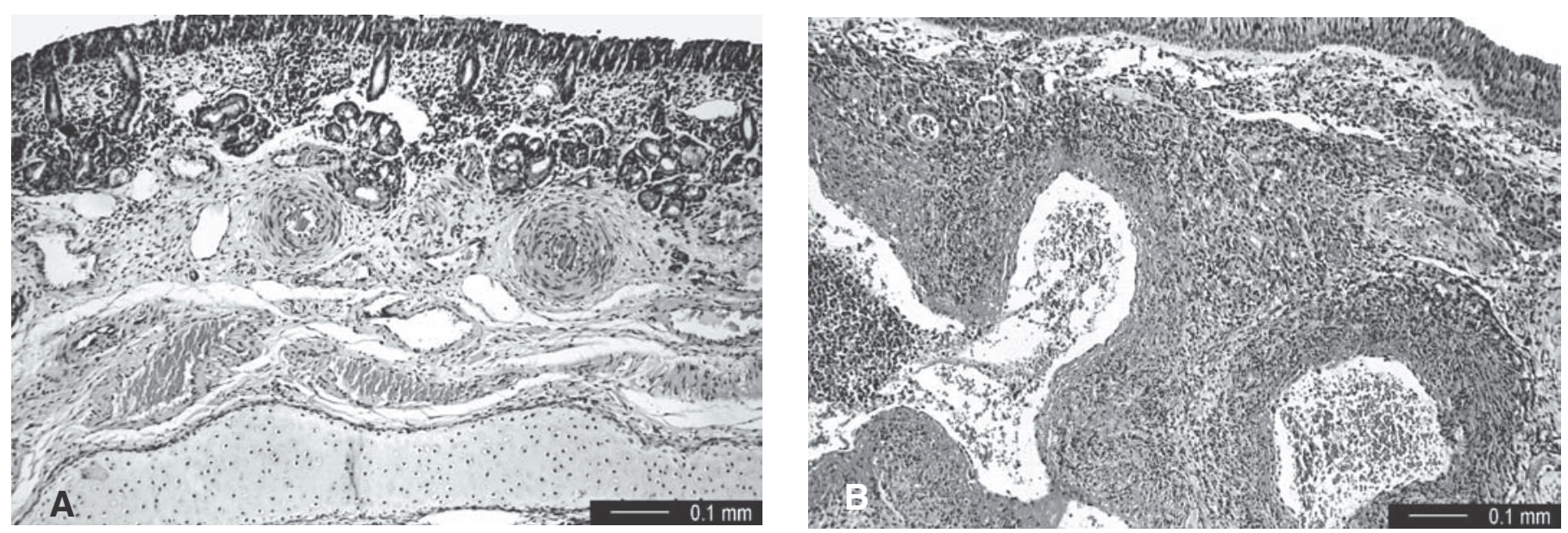

Fig. 6. Febre catarral maligna (FCM) em bovinos no Rio Grande do Sul. Aspecto histológico das fossas nasais. (A) Bovino normal. (B) Bovino com FCM. As arteríolas da submucosa estão afetadas por infiltrado inflamatório na adventícia e média e pode-se observar hialinização da túnica média. O epitélio nessa região está íntegro. HE, obj. 40.

achados consistiam de três categorias de lesões: (1) lesões vasculares, (2) necrose de epitélios com infiltrado inflamatório da lâmina própria e (3) acúmulo de células inflamatórias mononucleares em diversos órgãos (Fig. 3 e 4). A lesão vascular caracterizava-se por infiltrado de células mono-nucleares (linfoblastos, linfócitos, plasmócitos e histiócitos), na túnica média, adventícia e espaço perivascular associado a necrose fibrinóide da parede vascular que afetavam principalmente artérias de pequeno calibre e arteríolas e ocorriam em múltiplos órgãos (Fig. 5 e 6). Lesões vasculares características foram freqüentemente observadas no sistema nervoso central e rim. Os acúmulos de células inflamatórias em diversos órgãos tinham também características mononucleares semelhantes aos descritos nas artérias. Em alguns órgãos, como rim, fígado e globo ocular, esses acúmulos inflamatórios eram suficientemente grandes para serem percebidos macroscopicamente. Hiperplasia linfóide foi outro achado histológico freqüente. 


\section{DISCUSSÃO}

No presente estudo, FCM foi observada em bovinos de 15 propriedades do Rio Grande do Sul, num período de 30 anos. 0 diagnóstico na maioria dos surtos foi baseado nos sinais clínicos e achados de necropsia e confirmado pela histopatologia. Em dois surtos, o diagnóstico foi confirmado pela detecção de DNA viral de OvHV-2 por PCR e, num deles, por transmissão experimental da doença a bovinos (Garmatz et al. 2004).

A FCM-OA pode ocorrer de forma esporádica ou em surtos com vários casos (Smith 2002). Neste estudo, a doença ocorreu na forma esporádica (1-3 bovinos por propriedade) em nove ocasiões (60\%), enquanto, em seis fazendas (40\%), a FCM ocorreu de forma epizoótica, afetando vários bovinos em cada rebanho.

As taxas de morbidade de $2,4 \%$ a $20 \%$, verificadas nas 15 ocorrências de FCM aqui relatadas, indicam que a doença é importante no Estado. A taxa de letalidade foi próxima de $100 \%$ na maioria das propriedades investigadas, mas uma taxa de $83,3 \%$ foi verificada numa propriedade, indicando que a FCM em bovinos nem sempre é fatal, como se supunha (Selman et al. 1974), a ponto de o diagnóstico de FCM ser retificado, caso o bovino afetado se recuperasse. Com o advento de técnicas moleculares de diagnóstico, como a PCR, foi possível estabelecer que bovinos recuperados de FCM e portadores crônicos do vírus não são incomuns (O'Toole et al. 1995, O'Toole et al. 1997, Otter et al. 2002) e que sequielas da doença incluem arteriopatia obliterante crônica (O'Toole et al. 1995).

Tem sido descrito que os surtos de FCM-OA ocorrem em bovinos preferencialmente na primavera e verão (Selman et al. 1974). Essa tendência foi também verificada na maioria dos casos deste relato. Doze dos 15 relatos de FCM aqui descritos ocorreram de outubro a março.

O período de incubação da FCM é longo e pode se estender de 3 a 10 semanas, e a duração do curso clínico da doença aguda é de 3 a 7 dias, podendo haver casos hiperagudos de um dia de evolução (Smith 2002). No Rio Grande do Sul, o período de incubação em bezerros experimentalmente inoculados com sangue de bovinos com sinais clínicos avançados de FCM foi de 15-27 dias (Garmatz et al. 2004).

Em geral, um diagnóstico clínico presuntivo de FCM em bovinos não apresenta problemas, quando ocorrem os sinais clínicos característicos descritos na maioria dos casos deste relato. No entanto, há casos em que o diagnóstico clínico é difícil. Isso pode ser exemplificado neste estudo; em três das 15 propriedades onde ocorreram casos de FCM, foram observados apenas febre, anorexia, distúrbios nervosos e diarréia nos bovinos afetados, e, em duas outras, esses sinais eram acrescidos apenas de opacidade da córnea. Esses sinais clínicos são pouco específicos, o que dificulta o diagnóstico diferencial com base somente no exame clínico. No entanto, em todos os casos necropsiados, foram observadas alterações histológicas características que permitiram o diagnóstico definitivo de FCM. A tríade de alterações histológicas da FCM consiste de vasculite, acúmulos de células inflamatórias mononucleares em vários tecidos e necrose dos epitélios de revestimento (Garmatz et al. 2004). Na vasculite, ocorre necrose fibrinóide da parede de artérias e veias e infiltração de linfoblastos, linfócitos e macrófagos na média, adventícia e espaço perivascular (Barnard et al. 1994). Essas lesões estavam presentes em todos os casos de FCM em bovinos deste estudo e são altamente sugestivas da doença (Barker et al. 1993). No entanto, pode ser necessário examinar muitos cortes antes de encontrá-las. Os melhores locais para se observar essa lesão são a rete mirabile carotídea (Garmatz et al. 2004), encéfalo, leptomeninges, rim, fígado, cápsula da adrenal e qualquer área do trato digestivo (Barker et al. 1993). Essas devem ser, portanto, as áreas a serem colhidas em formol na necropsia de casos suspeitos de FCM, já que o isolamento em cultura de células do vírus da FCM-OA não é ainda uma opção possível. A técnica para coleta da rete mirabile carotídea foi recentemente descrita (Barros \& Marques 2003).

Presume-se que a transmissão da FCM-OA para bovinos ocorra pelo contato com ovinos em época de parição, de modo semelhante ao que ocorre em relação aos gnus em casos de FCMGA. Nas ocorrências de FCM relatadas neste estudo, a presença de ovinos em contato com os bovinos afetados foi investigada em apenas 9 ocasiões, e esse contato foi confirmado em todas elas; como é geralmente aceito que os ovinos sejam portadores do vírus da FCM e que transmitam o vírus para bovinos (Plowright 1990), a observação desse dado epidemiológico é importante. No entanto, há relatos de casos da infecção transplacentária de FCM em bovinos (O'Toole et al. 1997) e bisões (Schultheiss et al. 1998), e a manutenção do vírus em animais que nasçam infectados é outra possibilidade. Animais silvestres como veados também desenvolvem a doença (Driemeier et al. 2002) e poderiam ser portadores.

Os eventos principais na patogênese da FCM parecem ser a infecção viral e desregulação de uma população de linfócitos. A perda da atividade dos linfócitos supressores facilitaria a proliferação linfóide observada na doença, enquanto a atividade descontrolada das células NK seria responsável pela destruição tecidual (Smith 2002).

Os resultados deste levantamento indicam que distúrbios nervosos são comuns na FCM dos bovinos e que essa doença deve ser sempre considerada como uma possibilidade no diagnóstico diferencial das doenças do sistema nervoso central de bovinos. No presente estudo, sinais de distúrbios nervosos foram observados em bovinos de 9 propriedades afetadas. No entanto, vasculite dos vasos cerebrais e encefalite foram descritas no exame histológico realizado no encéfalo de bovinos afetados em 14 das 15 propriedades pesquisadas. É possível, portanto, que os sinais clínicos de distúrbios nervosos tenham sido negligenciados em alguns casos. Outras formas de meningoencefalites não-supurativas a vírus diagnosticadas em bovinos, no Brasil, como raiva, infecção por herpesvírus bovino tipo-5 (Sanches et al. 2000), doença de Aujeszky (Bauer 1955) e outras reações inflamatórias do encéfalo de bovinos, podem ser diferenciadas dos casos de FCM pelas alterações histológicas características de cada uma (Rech et al. 2004).

O diagnóstico diferencial de FCM em bovinos inclui outras doenças a vírus, como febre aftosa (FA), estomatite vesicular (EV), diarréia viral bovina-doença das mucosas (BVD-MD), língua azul (LA), peste bovina (PB) e intoxicações por arsênico (Smith 2002), pelo cogumelo Ramaria flavo-brunnescens (Santos et al. 1975) e por Amaranthus spp (Torres et al. 1997).

Na FA e na EV, ocorrem altas taxas de morbidade e baixas 
taxas de letalidade (Lemos \& Lima 2004), ao contrário das taxas relativamente baixas de morbidade e altas de letalidade observados na FCM. Na FA e na EV, não ocorre opacidade da córnea, e o epitélio da língua e da pele interdigital fica brancacento e elevado, desprendendo-se facilmente na fase inicial dos sinais clínicos (Lemos \& Lima 2004).

Várias manifestações têm sido associadas à infecção pelo vírus da diarréia viral bovina (BVDV). Dessas, a manifestação clínica mais difícil de diferenciar clinicamente de FCM é a MD, que geralmente ocorre em bovinos jovens com morbidade baixa e mortalidade perto de $100 \%$ após um curso clínico de 3-10 dias (Grooms et al. 2002). A MD ocorre quando bovinos persistentemente infectados e tolerantes a uma cepa não-patogênica do BVDV são infectados por uma cepa patogênica desse vírus (Bolin 1995). Como as taxas de morbidade e letalidade, os sinais clínicos e os achados de necropsia da FCM e da MD são bastante semelhantes, o diagnóstico diferencial dessas duas doenças é, talvez, o mais difícil. A histopatologia pode ajudar, mas mesmo assim as semelhanças existem, pois necrose hialina e fibrinóide das artérias mesentéricas e da submucosa do intestino são observadas com frequiência e ocasionalmente ocorrem também no miocárdio, cérebro e córtex adrenal (Barker et al. 1993). Recentemente um caso de meningoencefalite pelo tipo 2 do BVDV foi relatado em um bovino de 15 meses (Blas-Machado et al. 2004). No entanto, as lesões vasculares na MD são menos difusas, e a arterite fibrinóide com intenso infiltrado mononuclear da média e da adventícia nos vasos da rete mirabile carotídea é um achado típico da FCM (Barker et al. 1993).

LA é uma doença infecciosa não contagiosa de ovinos, mas é pouco frequiente em bovinos (Baldwin et al. 1991). Quando ocorre em bovinos, a doença é discreta e apresenta ulcerações orais, crostas no focinho, inflamação no rodete coronário, afrouxamento dos cascos, claudicação, abortos, infertilidade (Barker et al. 1993). Apenas $1-10 \%$ dos bovinos infetados pelo vírus da LA desenvolvem a doença, e a mortalidade é baixa. Esses dados clínicos e epidemiológicos permitem a diferenciação entre LA de FCM. Na necropsia, uma lesão característica de LA em ovinos e bovinos são as hemorragias na íntima da artéria pulmonar próximo à saída do ventrículo direito (Baldwin et al. 1991).

A PB é uma doença exótica no Brasil, e portanto, a população bovina no país não possui anticorpos. Assim, caso a doença fosse introduzida, os surtos seriam explosivos, com taxas de morbidade muito além dos da FCM (Rossiter 1994). Os sinais clínicos aparecem após um período de incubação que pode variar de 3 a 4 dias, mas que geralmente é de 4 a 5 dias e incluem febre, erosões na cavidade oral, corrimento nasal e ocular seroso mucopurulento, leucopenia, depressão, anorexia, diarréia e desidratação (Mebus 1998). Na necropsia, observam-se erosões na cavidade oral, faringe, esôfago e, mais raramente, nos pré-estômagos. A mucosa do abomaso está avermelhada, e há úlceras sobre as placas de Peyer do intestino, semelhantes às que ocorrem na MD (Rossiter 1994). Alterações histológicas características de PB permitem a diferenciação de FCM: necrose disseminada do tecido linfóide incluindo as placas de Peyer e formação de células sinciciais multinucleadas no epitélio escamoso de revestimento do tubo digestivo, por vezes associadas a inclusões intracitoplasmáticas eosinofílicas (Rossiter 1994, Mebus 1998).
Casos agudos de intoxicação por arsênico podem ocorrer em bovinos 3-12 dias após a ingestão dessa substância tóxica. Ocorre anorexia, diarréia hemorrágica, ulcerações e erosões em todo o trato gastrintestinal, desidratação e fraqueza. Embora alguns desses sinais possam lembrar FCM, não há febre ou opacidade da córnea e, no lugar das lesões histológicas características de FCM, ocorrem necrose tubular tóxica e necrose hepática multifocal (Bahri \& Romdane 1991, Plumlee 2002). O diagnóstico definitivo é feito pelos dados epidemiológicos indicando uma fonte dessa substância tóxica e pelo achado de níveis elevados de arsênico no fígado, rim e conteúdo gastrintestinal; níveis-traços não são diagnósticos, pois pequenas quantidades de arsênico são sempre encontradas em plantas e no solo (Plumlee 2002).

A intoxicação pelo cogumelo Ramaria flavo-brunnescens (mal do eucalipto) ocorre em bovinos e ovinos com acesso a bosques de eucalipto. Bovinos afetados apresentam ulceração da cavidade oral e dos cornetos, opacidade da córnea e afrouxamento da capa córnea dos cascos e chifres. Na necropsia, observam-se ainda úlceras no esôfago e abomaso (Santos et al. 1975). Esses sinais já provocaram a confusão dessa toxicose com doenças virais que produzem ulcerações no trato digestivo, como é o caso da FCM e FA; um exemplo disso é que o mal do eucalipto foi um dos diagnósticos extra-oficialmente aventados durante o surto de FA em bovinos no município de Jóia, no RS, em agosto de 2000. Há, no entanto, várias considerações epidemiológicas, clínicas e anátomo-patológicas que permitem a diferenciação dessas doenças. $\mathrm{O}$ mal do eucalipto tem ocorrência sazonal que coincide com o ciclo vegetativo do cogumelo (fevereiro-julho), somente ocorre em bovinos que têm acesso a matos de eucalipto e apresenta sinais clínicos característicos como perda dos pêlos da vassoura da cauda e atrofia das papilas da língua. Na histopatologia, há necrose dos epitélios de revestimento (Santos et al. 1975), mas não ocorrem as lesões vasculares características da FCM.

A intoxicação por plantas nefrotóxicas como Amaranthus spp pode ocorrer em bovinos com taxas de 50\%-100\% (Torres et al. 1997). Nesses casos, freqüentemente há um corrimento nasal, e a uremia resultante da lesão renal causa úlceras recobertas por fibrina na mucosa da cavidade oral, do esôfago, do pré-estômagos e do abomaso. Esses achados clínicos e de necropsia podem ser confundidos com lesões de FCM e de outras doenças víricas que causam ulcerações da mucosa do trato digestivo em bovinos (Lemos et al. 1993). No entanto, a intoxicação por Amaranthus spp tem ocorrência sazonal (fim de verão início de outono, quando a planta está em frutificação), não cursa com febre ou opacidade de córnea e em geral, apresenta lesões de mucosa menos difusas (Lemos et al. 1993). Embora possa ocorrer necrose hialina dos vasos da submucosa intestinal (Torres et al. 1997), as lesões de vasculite e acúmulos inflamatórios mononuclares característicos de FCM não ocorrem, e há as lesões típicas de necrose tubular tóxica (Lemos et al. 1993, Torres et al. 1997).

O diagnóstico conclusivo de FCM-OA pode ser feito com base na epidemiologia, achados clínicos, de necropsia e histopatológicos, os quais foram relatados em detalhe neste estudo. O DNA viral de OvHV-2 pode ser detectado pela técnica de PCR em tecidos emblocados em parafina e em material fresco 
(por ex., sangue total) congelado (Garmatz et al. 2004). A inoculação em coelhos também pode ser empregada para confirmar o diagnóstico (Döbereiner \& Tokarnia 1959). A cultura de OvHV-2 não foi ainda conseguida.

Tratamentos de suporte têm sido usados em alguns casos de FCM em bovinos com relativo sucesso (Plowright 1990, O’Toole et al. 1997), mas não há tratamento específico ou vacinas eficazes contra a doença (Plowright 1990). Medidas de controle recomendadas incluem não colocar bovinos em contato com ovinos e isolar bovinos afetados de bovinos sadios (Otter et al. 2002).

\section{REFERÊNCIAS}

Bahri L.F. \& Romdane S.B. 1991. Arsenic poisoning in livestock. Vet. Human Toxicol. 33:264.

Baldwin C.A., Mosier D.A., Rogers S.J. \& Bragg C.R. 1991. An outbreak of disease in cattle due to bluetongue virus. J. Vet. Diagn. Invest. 3:252255.

Baptista F.Q. \& Guidi P.C. 1998. FCM no estado do Paraná. Hora Vet., Porto Alegre, 45:33-37.

Barker I.K., Van Dreumel A.A. \& Palmer N. 1993. The alimentary system, p.163-173. In: Jubb K.V.F., Kennedy, P.C. \& Palmer N. (ed.) Pathology of Domestic Animals. Vol. 2. 4th ed. Academic Press, San Diego. 747p.

Barnard B.J.H., Van der Lugt J.J. \& Mushi E.Z. 1994. Malignant catarrhal fever, p. 946-957. In: Coetzer J.A.W., Thomson G.R. \& Tustin R.C. (ed.) Infectious Diseases of Livestock with Special Reference to Southern Africa. Vol. 2. Oxford University Press, Cape Town. 1605p.

Barros C.S.L \& Marques G.H.F. 2003. Procedimentos para o Diagnóstico das Doenças do Sistema Nervoso Central de Bovinos. Depto Defesa Animal, Min. Agricultura, Pecuária e Abastecimento, Brasília. 50p.

Barros S.S., Santos M.N. \& Barros C.S.L. 1983. Surto de febre catarral maligna em bovinos no Rio Grande do Sul. Pesq. Vet. Bras. 3:81-86.

Bauer A.G. 1955. Primeira constatação do mal de Aujeszky no Rio Grande do Sul. Arq. Inst. Pesq. Vet. Desidério Finamor 1:15-16.

Blas-Machado U., Saliki J.T., Duffy J.C. \& Caseltine S.L. 2004. Bovine viral diarrhea virus type 2-induced meningoencephalitis in a heifer. Vet. Pathol. 41:190-194.

Bolin S.R. 1995. The pathogenesis of mucosal disease. Vet. Clin. North America (Food Anim. Pract.) 11:489-500.

Döbereiner J. \& Tokarnia C.H. 1959. Ocorrência da coriza gangrenosa dos bovinos no município de Serra Negra do Norte, Rio Grande do Norte. Arqs Inst. Biol. Animal, Rio de J., 2:65-82.

Driemeier D., Brito M.F., Traverso S.D., Cattani C. \& Cruz C.E.F. 2002. Outbreak of malignant catarrhal fever in brown brocket deer (Mazama gouazoubira) in Brazil. Vet. Rec. 151:271-272.

Figueiredo L.J.C., Castelo Branco M.B. \& Oliveira A.C. 1990. Aspectos clínicos e epidemiológicos da FCM. Anais $16^{\circ}$ Congresso Mundial de Buiatria, Salvador, p.666-671.

Garmatz S.L., Irigoyen L.F., Rech R.R., Brown C.C., Zhang J. \& Barros C.S.L. 2004. Febre catarral maligna em bovinos no Rio Grande do Sul: transmissão experimental para bovinos e caracterização do agente etiológico. Pesq. Vet. Bras. 24:93-106.

Grooms D., Baker J.C. \& Ames T.R. 2002. Diseases caused by bovine virus diarrhea virus, p.707-714. In: Smith B.P. (ed.) Large Animal Internal Medicine. Mosby, St. Louis. 1735p.

Lemos R.A., Barros C.S.L., Salles M.S., Barros S.S. \& Peixoto P.V. 1993. Intoxicação espontânea por Amaranthus spinosus (Amaranthaceae) em bovinos. Pesq. Vet. Bras. 13:25-39.

Lemos R.A.A. \& Lima H.W. 2004. Fundamentos de epidemiologia em febre aftosa. Escola de Qualificação Rural, Universidade Federal do Mato Grosso do Sul, Campo Grande. 59p.

Løken T., Aleksandersen M., Reid H. \& Pow I. 1998. Malignant catarrhal fever caused by ovine herpesvirus- 2 in pigs in Norway. Vet. Rec. 143:464-467.
Marques L.C, Alessi A.C., Bechara G.H., Tomaz B.V., Marques J.A \& Guerra L. 1986. Surto de febre catarral maligna em bovinos no estado de São Paulo. Arq. Bras. Med. Vet. Zootec. 38:719-729.

Mebus C.A. 1998. Rinderpest, p.332-338. In: Buisch W.W. Hyde J.L. \& Mebus C.A. (ed.) Foreign Animal Diseases. Comitttee on Foreign Animal Diseases of the United States Animal Health Association, Richmond, Virginia. 432p.

O’Toole D., LI H., Roberts S., Rovnak J., DeMartini J.C., Cavender J., Williams B. \& Crawford T.B. 1995. Chronic generalized obliterative arteriopathy in cattle: a sequel to sheep-associated malignant catarrhal fever. J. Vet. Diagn. Invest. 7:108-121.

O’Toole D., LI H., Miller D., Williams B. \& Crawford T.B. 1997. Chronic and recovered cases of sheep-associated malignant catarrhal fever in cattle. Vet. Rec. 140:519-524.

Oliveira A.C., Figueiredo L.J.C. \& Resende A.M. 1978. Casos de febre catarral maligna, ocorridos em Riachão de Jacuípe, Bahia. Descrição clínica e anátomo-patológica. 16ำ Congr. Bras. Med. Vet., Salvador, p.130. (Resumo)

Otter A., Pow I. \& Reid H.W. 2002. Outbreak of malignant catarrhal fever in Welsh black cattle in Carmarthenshire. Vet. Rec. 151:321-324.

Plowright W. 1990. Malignant catarrhal fever virus, p.123-150. In: Morein B. \& Dinter Z. (ed.) Virus Infections of Ruminants. Elsevier Science Publishers, Amsterdam, The Netherlands. 592p.

Plumlee K.H. 2002. Metals and other inorganic compounds, p.1637. In: Smith B.P. (ed.) Large Animal Internal Medicine. Mosby, St. Louis.

Rech R.R, Fighera R.A., Oliveira F.N \& Barros C.S.L. 2004. Meningoencefalite granulomatosa em bovinos em pastoreio de ervilhaca (Vicia spp). Pesq. Vet. Bras. 24(3):169-172.

Riet-Correa F., Méndez M.C., Schild A.L., Brod C.S. \& Bondan E.F. 1988. Doenças diagnosticadas no ano de 1987. Laboratório Regional de Diagnóstico, Editora Gráfica Universitária, UFPel, Pelotas, p.15-16.

Riet-Correa F., Tabosa I.M., Azevedo E.O., Medeiros R.M.T., Simões S.V.D., Dantas A.F.M., Alves C.J., Nobre V.M.T., Athayde A.C.R., Gomes A.A. \& Lima E.F. 2003. Doenças dos Ruminantes e Eqüinos no Semi-Árido da Paraíba. Febre catarral maligna. Semi-Árido em Foco, Patos, 1(1):1213.

Rossiter P.B. 1994. Rinderpest, p.735-757. In: Coetzer J.A.W., Thomson G.R. \& Tustin R.C. (ed.) Infectious Diseases of Livestock with Special Reference to Southern Africa. Vol. 2. Oxford University Press, Cape Town.

Sampaio F.A., Sampaio A.A. \& Dacorso Filho P. 1972. Surto de febre catarral maligna em Campos, RJ. $8^{\circ}$ Congr. Bras. Med.Veterinária, Brasília, p.275. (Resumo)

Sanches A.W.D., Langohr I.M., Stigger A.L. \& Barros C.S.L. 2000. Doenças do sistema nervoso central em bovinos no Sul do Brasil. Pesq. Vet. Bras. 20:113-118.

Santos M.N., Barros S.S. \& Barros C.S.L. 1975. Intoxicação em bovinos pelo cogumelo Ramaria flavo-brunnescens. Pesq. Agropec. Bras. 10:105109.

Schultheiss P.C., Collins J.K., Austgen L.E. \& DeMartini J.C. 1998. Malignant catarrhal fever in bison, acute and chronic cases. J. Vet. Diagn. Invest. 10:255-262.

Selman I.E., Wiseman A., Murray M. \& Wright N.G. 1974. A clinicpathological study of bovine malignant catarrhal fever in Great Britain. Vet. Rec. 94:483-490.

Silva S.M.M.S., Cavalcante H.S., Viana G.E.N., Barbosa A.A. \& Silva S.A.V. 2001. Surto de febre catarral maligna. 9 Enapave, Pirassununga, p.70. (Resumo)

Smith B.P. 2002. Malignant catarrhal fever, p.714-716. In: Ibid. (ed.) Large Animal Internal Medicine. Mosby, St. Louis.

Torres M.B., Kommers G.D., Dantas A.F.M. \& Barros C.S.L. 1997. Redroot pigweed (Amaranthus retroflexus) poisoning of cattle in southern Brazil. Vet. Human Toxicol. 39:94-96.

Torres S. 1924. Oca, mal do chifre ou coryza gangrenosa dos bovinos. Bolm Soc. Bras. Med. Vet. 1:144-159. 